\title{
Modeling the Process of Transportation of Seed Cotton through the Parameters of the Food Zone
}

\author{
Akmal Umarov', Dilmurat Kurbanov¹, Muazzam Kenjayeva1, Botir Mardonov² \\ ${ }^{1}$ Namangan Institute of Engineering and Technology, Namangan, Uzbekistan \\ ${ }^{2}$ Tashkent Institute of Textile and Light Industry, Tashkent, Uzbekistan \\ Email: akmal.umarov@mail.ru,qurbonov.dil@mail.ru,muazzam_kenjayeva@mail.ru
}

How to cite this paper: Umarov, A., Kurbanov, D., Kenjayeva, M. and Mardonov, B. (2021) Modeling the Process of Transportation of Seed Cotton through the Parameters of the Food Zone. Engineering, 13, 493-501.

https://doi.org/10.4236/eng.2021.139035

Received: April 29, 2021

Accepted: September 27, 2021

Published: September 30, 2021

Copyright $\odot 2021$ by author(s) and Scientific Research Publishing Inc. This work is licensed under the Creative Commons Attribution International License (CC BY 4.0).

http://creativecommons.org/licenses/by/4.0/

\begin{abstract}
In the process of separating the fiber from the seed, the density of the seed roll in the roll box of the saw gin is constantly changing. With an increase in the density of the seed roll, the quality indicators of fiber and seed deteriorate, energy consumption increases, machine breakdowns increase, and with a decrease in density, the productivity of the machine decreases. For this reason, the regulation of the density of the seed roll is one of the important problems in the ginning process. For this, the speed of rotation of the feed rollers changes, which, with an increase in speed, the mass of cotton increases, and with a decrease, it decreases. Thus, the density of the seed roll is controlled. The article describes the problem of regulating the density of a seed roll in a saw gin of the DP series, an overview of the work on regulating the operation of the machine is given. In this work, the force of cotton pressure between two feed rollers is also theoretically investigated. Graphs of changes in the force of cotton pressure between two rollers are plotted depending on various initial pressure forces. The results of the study will be used in the further improvement of the cotton feeding regulation in order to maintain the optimum density of the seed roll, which will preserve the quality of the fiber and seeds while increasing the productivity of the machine.
\end{abstract}

\section{Keywords}

Cotton, Saw Gin, Feed Rollers, Roll Box, Seed Roll, Productivity, Pressure, Density, Cotton Movement Speed, Coefficient of Elasticity of Cotton Mass

\section{Introduction}

The Republic of Uzbekistan pays great attention to the rapid development of 
production of finished products with added value based on deep processing of cotton raw materials, providing competitive cotton products in the domestic and foreign markets based on the modernization of the cotton ginning industry.

Maintaining the primary quality indicators of fiber and seed in the process of fiber ginning, the creation of simple designs of equipment for the processes of separating fiber from seed and feeding with raw cotton, with low material consumption and energy consumption, is an important task [1] [2].

Research work carried out to date has been aimed at solving some problems of improving the processes and machines for separating cotton fiber from the seed, as well as improving the process of feeding saw gins with cotton, regulating the feeding of saw gins, as a result of which, to some extent, technology and the technology of the primary processing of cotton, the qualitative and quantitative indicators of the products obtained have been improved. However, the problems of creating a resource-saving technology for power management of the ginning process with raw materials, in accordance with the density level of the seed roll of saw gin while preserving the natural properties of cotton, have not been sufficiently studied [3] [4].

In the study [5], the process of ginning on gins of the DP brand was considered, a device for regulating the density of a seed roll by changing the speed of the motor of the feed rolls with an inverter was proposed, a device for regulating the position of the roll box depending on the current load of the saw cylinder motor was proposed, experiments were carried out on determination of the dependence of the load current of the motor of the saw cylinder and the movement of the roll box.

At present, the gin of the DP series is the most widely used in the cotton ginning industry of the CIS countries, which has rather good technological indicators. But the problem of regulating the density of the seed roll has not been completely solved [6]. The problem of optimizing the density of the seed roll can be solved by improving the geometry of the feed hopper and adjusting the frequency of rotation of the feed rolls of the feeder [7]. The analysis carried out to select the law for regulating the frequency of rotation of the feeding characteristics of the controlled object is the multi-capacity of the fiber separation line, a relatively large delay in regulation, and the smoothness of the nature of the load change [8].

In the article [9], it was proposed to install side accelerators that control the speed and density of the seed roll in the roll box of the saw gin.

When studying processes in equipment, there is a definition and change of speeds, loads, operating time and other working bodies. In saw gins, the speed of the feed rollers is changed to adjust the density of the seed roll. We proposed changing the speed of the feed rolls by an inverter. Another advantage of the inverter is the ability to observe some of the working bodies during operation [10]. When the signal arriving at the inverter changes, the speed of the feed rollers changes synchronously. This shows the possibility of using a inverter as a regulator of the mass of seed cotton entering the roll box of the saw gin [11]. 
The work [12] provides information on the influence of the density of the seed roll formed in the roll box on the load of the saw cylinder drive, machine performance, on the quality of fiber and seeds. As a result of research in order to maintain the density of the seed roll in the optimal range, the author proposes a saw gin with a system for regulating the density of the seed roll [13].

Maintaining the optimum density of the seed roll in the saw gin is the most important technological and economic norm that can be solved by adjusting the speed of the electric drives of the gin feeders. To solve this problem, a regulator has been developed, the structure of which is given in [14] [15]. Tests carried out in production conditions have shown that the use of the developed device allows to ensure a stable density of the seed roll in optimal conditions in relation to without operator intervention, in accordance with the instructions, provides an improvement in the quality of cotton fiber by an average of one class [16].

In the article, stake accelerator has proposed on the side of the roll box in order to increase the productivity of the gin machine [17]. The effect to the raw material of the proposed stakes was studied. Movement differential equation of the seed roller was made up and necessary graphics were taken based on laws [18] [19].

\section{Materials and Methods.}

The condition of the material between the star-shaped feed rollers in the feed zone is determined by the pressure $P$, density $\rho$ and speed $V$ of the cotton. Its parameters are assumed to be dependent on the coordinate variable $x$. Here the origin of coordinates is set in the middle of the section of the feeding zone, and the axis $o x$ is directed from bottom to top (Figure 1).

We will take the process stationary and assume that the distance between the rollers is filled with raw material. Let's separate the element $\mathrm{d} x$ from the cotton mass and compose the Euler equation for this element [9] [20]:

$$
b \delta p \frac{\mathrm{d} V}{\mathrm{~d} x}=-\frac{\mathrm{d}(p b)}{\mathrm{d} x}+p g(\sin \alpha+\theta \cdot f \cos \alpha)
$$

here, $b=b_{0}+\frac{x^{2}}{R} ; \sin \alpha \approx \frac{x}{R} ; \cos \alpha \approx 1 ; b_{0}=l-2 R ; f$-friction force between roller and cotton, $\mathrm{N}$.

Equation (1) consists of the unknown pressure $P$, density $\rho$ and speed $V$ of the raw material between the rollers. To determine them, we will use the following conditions:

1) The law of conservation of mass of flow motion in a stationary mode

$$
Q=\rho V b L=Q_{0}=\text { const }
$$

here, $Q$-mass of flow moving per unit of time (feeder productivity), $\mathrm{kg} / \mathrm{h}$; $L$-roller length, $\mathrm{mm}$.

In Equation (1), the quantity $\theta$ is related to the sign of the relative speed $V_{0}$ ( $V_{0}-$ is the speed of the saw cylinder) and is determined as follows:

$$
\begin{aligned}
& \text { At } z>0, \theta(z)=1 ; \\
& \text { At } z<0, \theta(z)=-1 .
\end{aligned}
$$




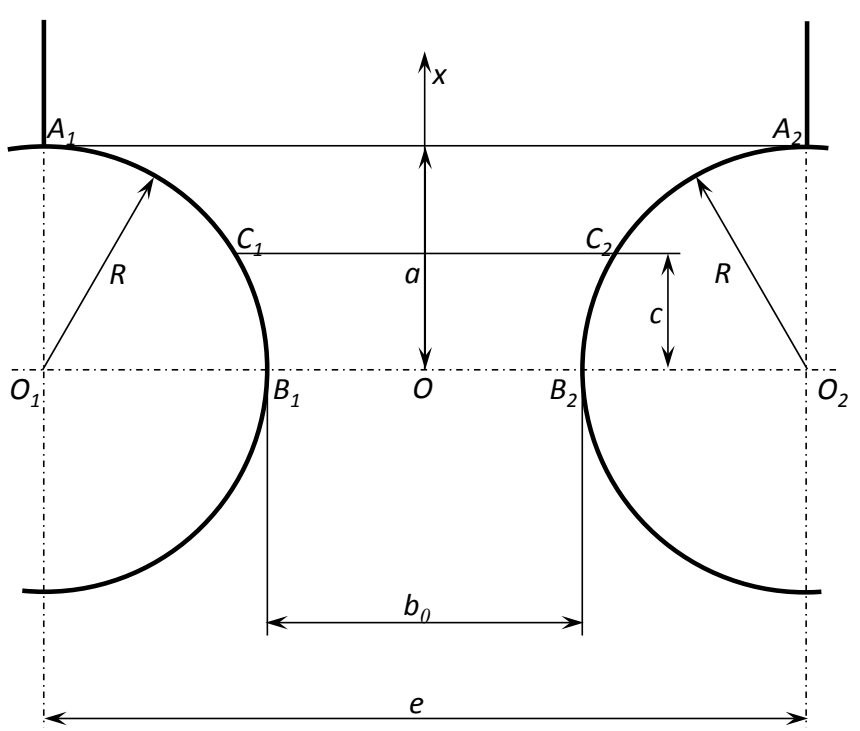

Figure 1. Scheme of movement of raw material between two rollers.

2) The equation of state of cotton as a whole medium, expressing the relationship between pressure and density

$$
P=\rho_{0}\left(1+A\left(P-P_{0}\right)\right)
$$

Using (2) and (3), we establish a relationship between pressure and speed:

$$
V=\frac{Q_{0}}{L b \rho_{0}\left[\left(1+A\left(P-P_{0}\right)\right)\right]} \approx \frac{Q_{0}}{L \rho_{0} b}\left[1-A\left(P-P_{0}\right)\right]
$$

From this equation we get the following:

$$
\frac{\mathrm{d} V}{\mathrm{~d} x}=\frac{Q_{0}}{L \rho_{0}}\left[-\frac{b^{\prime}}{b^{2}}\left[1-A\left(P-P_{0}\right)\right]-\frac{A}{b} \frac{\mathrm{d} P}{\mathrm{~d} x}\right]
$$

Using (2), (3) and (5) we write Equation (1) in relation to pressure $P(x)$ :

$$
\begin{aligned}
& \frac{Q_{0}^{2}}{L^{2} \rho_{0}}\left\{-\frac{b^{\prime}}{b^{2}}\left[1-A\left(P-P_{0}\right)-\frac{A}{b} \frac{\mathrm{d} P}{\mathrm{~d} x}\right]\right. \\
& \left.=-\frac{\mathrm{d} P}{\mathrm{~d} x} b-p b^{\prime}+\rho_{0} g b\left[1+A\left(P-P_{0}\right)\right]\left(\frac{x}{R}+\theta f\right)\right\}, \quad 0<x<a
\end{aligned}
$$

Equation (6) is reduced to the following form:

$$
\begin{gathered}
\frac{\mathrm{d} P}{\mathrm{~d} x}=F_{1}(x) P+F_{2}(x), 0<x<a \\
F_{1}(x)=-\frac{b^{\prime}+F_{20}(x)}{b F_{0}(x)}, \\
F_{2}(x)=\frac{F_{20}(x) P_{0}+F_{10}(x) b^{\prime}+P_{0} g\left(\frac{x}{R}+\theta f\right) b}{b F_{0}(x)}, \\
F_{10}=\frac{Q_{0}^{2} A}{L^{2} b^{2} P_{0}}, F_{0}=1-F_{10}(x),
\end{gathered}
$$




$$
F_{20}(x)=F_{10}(x) b^{\prime}-P_{0} g A b\left(\frac{x}{R}+\theta f\right) .
$$

Equation (7) is a variable linear differential equation with respect to $P(x)$, we integrate it under the boundary conditions $P=P_{H}, x=0$.

Let us carry out a qualitative analysis of the movement of the cotton mass in the feeding zone to select the sign of the variable $\theta$ at the coefficients of Equation (7).

Consider the right roller. Here, the speed of rotation of the points of the segment $x=0$ is greater than the speed $\omega R$ along the arc $A_{2} C_{2} B_{2} \quad(\omega$-angular velocity of the roller; $R$-radius of the roller).

The relative speed of the parts in the feed zone $\left(V>V_{0}\right)$ is positive and therefore the direction of the friction force has a positive direction of the axis $O X$. For this reason, for this segment, we take the sign $\theta$ in the tangency zone along the arc $B_{2} C_{2}$ to be positive. The second end point $x=a$ has a critical speed $\omega R$, i.e. the relative velocity in the feeding zone of the cotton will be negative, which means that in the zone of contact with the segment $x=a$ (along the $\operatorname{arc} C_{2} A_{2}$ ) the friction is directed towards the negative side of the axis $O X$. In this zone $\theta$, you must accept with a minus sign. In this zone, the mass is clamped between the feed rollers, the friction force will be active and directed in the opposite direction of the axis $O X$. The friction force in another zone of contact with the segment $x=0$ resists the movement of the mass, so it is directed in the opposite direction of the axis $O X$.

The segment $x=c \quad(0<c<R)$, the speed of which is equal to the linear speed of the roller, is the boundary of the above zones. If at the boundaries $x=0$ and $x=a$ applied pressures equal $P=0$ and $P=P_{H}$, then to determine $P(x)$ in the zone $0<x<a$, Equation (7) must be integrated in the zone $x>0$ under the condition $P(0)=0$ for $\theta$ accepting the plus sign, under the condition $P=P_{H}$ for $\theta$ taking the minus sign. If for $P(x)$ a given mass in the feeder moves, in the zone $x=c$ from the condition of equality of pressure $P_{1}(x) \quad(x>0)$ and $P_{2}(x) \quad(x<a)$, the curved lines intersect with the abscissa at a point $x=c$. This point is the border of two zones. If we find this point, then from the equation $L \omega R \rho(c) b(c)=Q_{0}$ we determine the required speed of the rollers to obtain the required performance of the feeder

$$
\omega=\frac{Q_{0}}{L \rho(c) b(c) R}
$$

According to the above conditions of Equation (7), for each zone, we write the following:

$$
\frac{\mathrm{d} P_{1}}{\mathrm{~d} x}=F_{1}^{(1)}(x) P_{1}+F_{2}^{(2)}(x)=F_{1}^{(1)}(x)+F_{2}^{(1)}(x), x>0
$$

here, $F_{1}^{(1)}(x)=-\frac{b^{\prime}+F_{21}(x)}{b F_{0}(x)}$;

$$
F_{2}^{(1)}(x)=\frac{F_{21}(x) P_{0}+F_{10}(x) b^{\prime}+P_{0} g\left(\frac{x}{R}+f\right) b}{b F_{0}(x)} ;
$$




$$
F_{21}(x)=F_{10}(x) b^{\prime}-P_{0} g A b\left(\frac{x}{R}+f\right) .
$$

We integrate Equation (9) under the condition $P_{1}(0)=0$ and obtain the following:

$$
P_{1}=\mathrm{e}^{F_{1}^{1}(x)} \int_{0}^{x} F_{2}^{1}(x) \mathrm{e}^{-F_{1}^{\prime}(x)} \mathrm{d} x
$$

In the zone $0<x<a$, we write Equation (7) as follows:

$$
\frac{\mathrm{d} P_{2}}{\mathrm{~d} x}=F_{1}^{(2)}(x) P+F_{2}^{2}(x)
$$

here, $F_{1}^{(1)}=-\frac{b^{\prime}+F_{22}(x)}{b F_{0}(x)}$;

$$
\begin{gathered}
F_{2}^{(2)}=\frac{F_{22}(x) P_{0}+F_{10}(x) b^{\prime}+P_{0} g\left(\frac{x}{R}-f\right) b}{b F_{0}(x)} ; \\
F_{22}=F_{10}(x) b^{\prime}-P_{0} g A b\left(\frac{x}{R}-f\right) .
\end{gathered}
$$

The solution to the last equation, satisfying the condition $P_{2}(a)=P_{H}$, has the following form:

$$
P_{2}=\mathrm{e}^{F_{1}^{(2)}(x)}\left[P_{0} \mathrm{e}^{-F_{1}^{(2)}(a)} \int_{x}^{a} \mathrm{e}^{-F_{1}^{(2)}(x)} F_{2}^{(2)}(x) \mathrm{d} x\right]
$$

The zone boundaries $x=c$ are defined by the following equation:

$$
\mathrm{e}^{F_{1}^{(1)}(c)} \int_{0}^{c} F_{2}^{(1)}(x) \mathrm{e}^{-F_{1}^{(1)}(x)} \mathrm{d} x=\mathrm{e}^{F_{1}^{(2)}(c)}\left[P_{0} \mathrm{e}^{-F_{1}^{(2)}(a)}-\int_{c}^{a} \mathrm{e}^{-F_{1}^{(2)}(x)} F_{2}^{(2)}(x) \mathrm{d} x\right]
$$

Using the obtained equations, we will construct graphs (Figure 2)

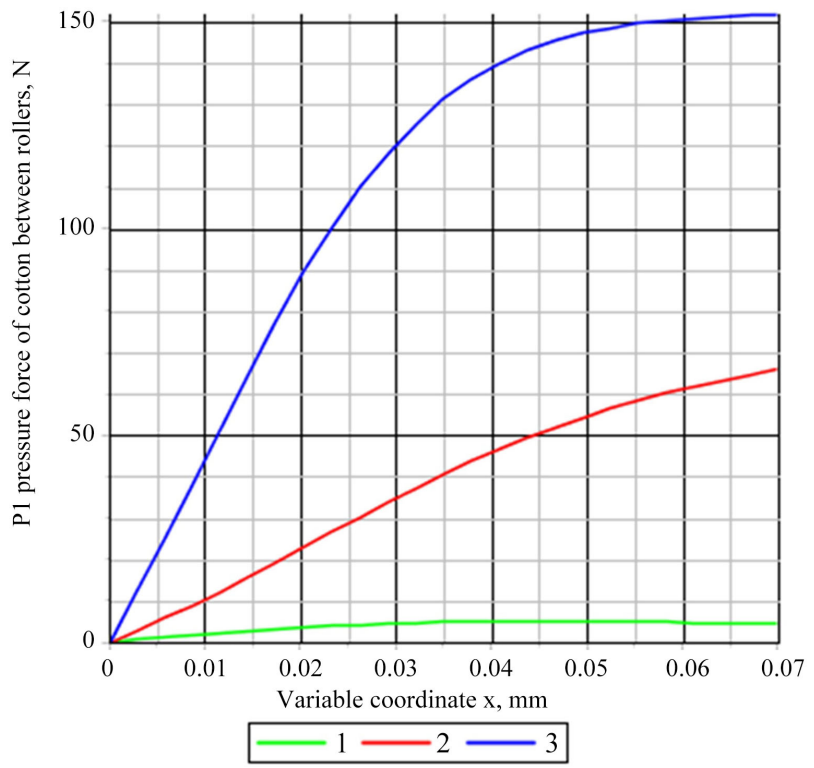

(a) 


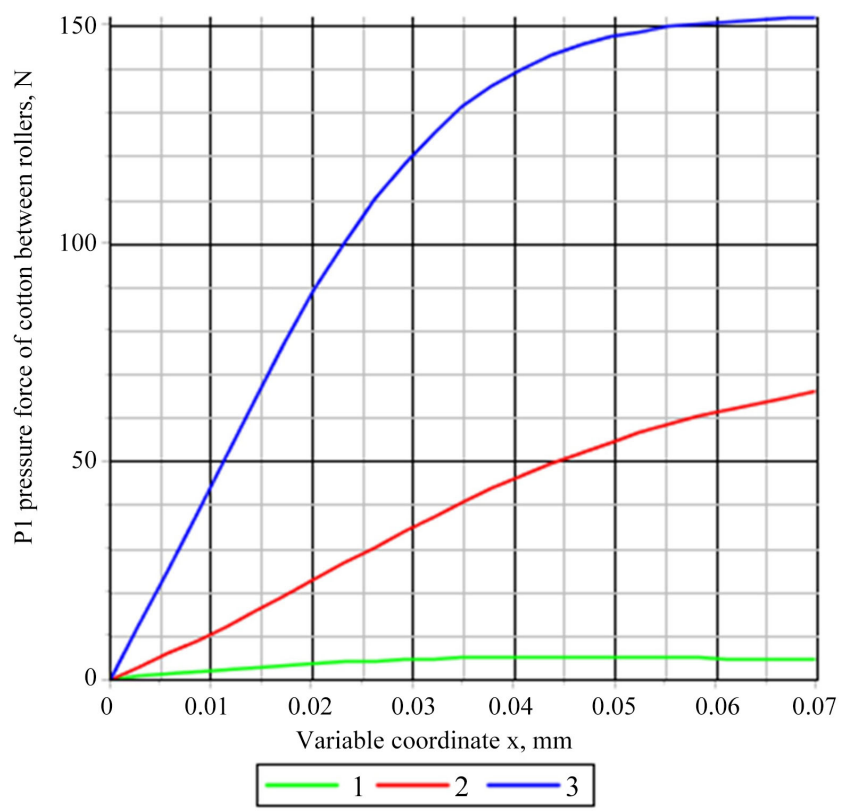

(b)

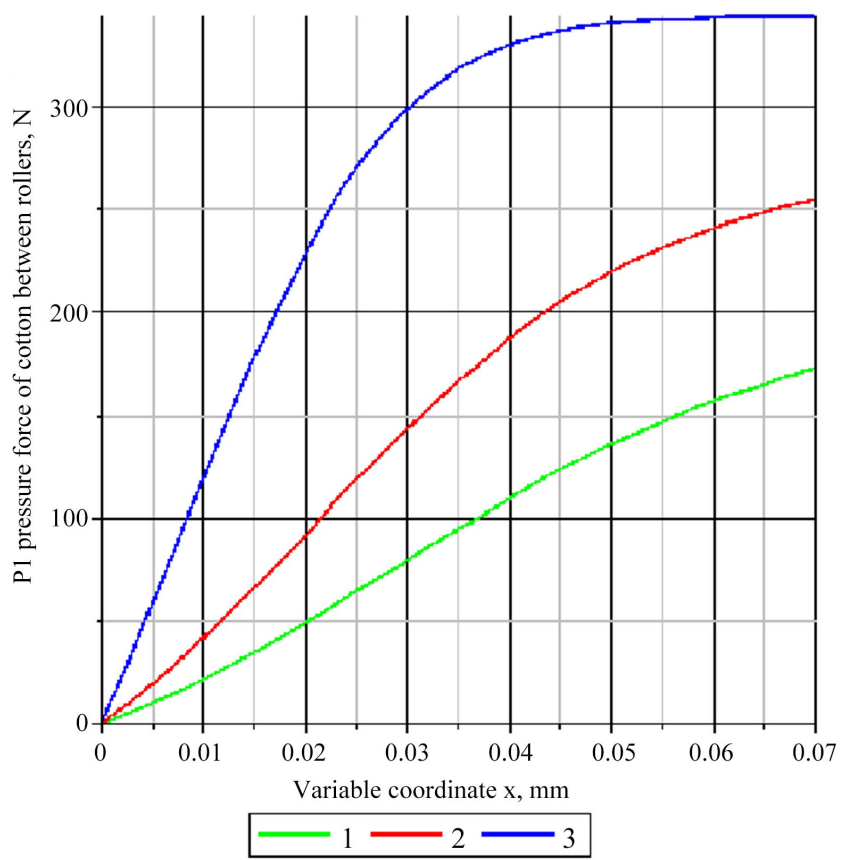

(c)

Figure 2. The regularity of the change in the force of pressure of cotton between two rollers depending on different initial forces of pressure $P_{0}=620 \mathrm{H} / \mathrm{m}^{2} \quad$ (a), $P_{0}=700 \mathrm{H} / \mathrm{m}^{2} \quad$ (b), $P_{0}=780 \mathrm{H} / \mathrm{m}^{2} \quad$ (c): $1-A=0.0017 \mathrm{~Pa}^{-1} ; 2-A=0.009 \mathrm{~Pa}^{-1} ; 3-A=0.0022 \mathrm{~Pa}^{-1}$.

For calculations, we will use the following initial data: $Q_{0}=0 \div 6000 \mathrm{~kg} / \mathrm{h}$; $a=70 \mathrm{~mm} ; R=70 \mathrm{~mm} ; b_{0}=100 \mathrm{~mm} ; f=0.2 ; \rho_{0}=64 \mathrm{~kg} / \mathrm{m}^{3}$; $L=2335 \mathrm{~mm}, n=0 \div 14 \mathrm{rpm}$. $A$-coefficient of elasticity of cotton mass, $A=0.0017 \mathrm{~Pa}^{-1} ; 0.009 \mathrm{~Pa}^{-1} ; 0.0022 \mathrm{~Pa}^{-1}$. 


\section{Conclusions}

As can be seen from Figure 2, the force of cotton pressure between the feed rollers, with an increase in the coefficient of porosity, obeys the regularity of growth along the coordinate $x$. This growth remains constant starting from $x=$ $0.05 \mathrm{~mm}$ at $A=0.0022 \mathrm{~Pa}^{-1}$.

The force of pressure of the cotton between the rollers, with an increase in the initial forces of pressure, obeys the regularity of growth along the coordinate $x$. This growth remains constant starting from $x=0.05 \mathrm{~mm}$ at $A=0.0022 \mathrm{~Pa}^{-1}$.

\section{Conflicts of Interest}

The authors declare no conflicts of interest regarding the publication of this paper.

\section{References}

[1] Umarov, A., Akhmedkhodzhaev, Kh., Sarimsakov, A. and Kenjaeva, M. (2018) Movement Differential Equation of Seed Roller Which Has Been Installed Stake Accelerator on the Roll Box of Gin Machine. Engineering, 10, 521-529. http://www.scirp.org/journal/eng https://doi.org/10.4236/eng.2018.108038

[2] Umarov, A. (2008) Investigation of the Regulation of the Density of the Seed Roll of Gin Stand. Natural and Technical Sciences ${ }^{\circledast}$, Moscow, No. 2 (34), 328-329.

[3] Sarimsakov, A., Muradov, R., Umarov, A. and Kurbanov, D. (2018) The Saw Gin Stand with Adjustable Movement of the Roll Box. Engineering, 10, 486-494. http://www.scirp.org/journal/eng https://doi.org/10.4236/eng.2018.108034

[4] Sharipjanovich, S.O., Kizi, K.M.Y. and Kizi, K.M.Y. (2020) Effective Ways to Improve the Cotton Drying and Cleaning Process. Journal NX-A Multidisciplinary Peer Reviewed Journal, 7, 22-25. https://journalnx.com/papers/20150908-cotton-drying-cleaning\%20.pdf

[5] Axmedxodjayev, Kh., Umarov, A. and Ortiqova, K. (2019) Investigation of the Ginning Process on ДП Series Saw Gin Stands. Engineering, 11, 523-530.

http://www.scirp.org/journal/eng https://doi.org/10.4236/eng.2019.118036

[6] Umarov, A.A. (2018) A Saw Gin with a System for Controlling the Density of a Seed Roll. Scientific- Technical Journal, 22, Article 33. https://uzjournals.edu.uz/ferpi/vol22/iss1/33

[7] Abduvakhidov, M.A. and Umarov, A.A. (2008) Research of Speed Regulation of Electric Drives of Gin Feeders. Natural and Technical Sciences ${ }^{\oplus}$, Moscow, No. 2 (34).

[8] Akramjon, S., Rustam, M., Akmal, U. and Dilmurat, K. (2018) Movement Differential Equation of Seed Roller Which Has Been Installed Stake Accelerator on the Roll Box of Gin Machine. Engineering, 10, 521-529. http://www.scirp.org/journal/eng https://doi.org/10.4236/eng.2018.108038

[9] Ishlinsky, A.Yu. (1982) Applied Problems of Mechanics. Part 1. The Science, Moscow, $360 \mathrm{p}$.

[10] Sarimsakov, A.U., Kurbonov, D.M. and Halikov, Sh.H. (2019) The Study of the 
Crucible Rotation of Raw Materials with a Practical Way. Scientific and Practical Journal "Economy and Society”, No. 12, 43-49. https://iupr.ru/nauchno_prakticheskiy_zhurnal_ekonomika_i_socium__12_67_ 2019_g_dekabr_

[11] Umarov, A.A., Ortikova, K., Sarimsakov, A.U. and Kurbanov, D. (2020) Analysis of the Control of Manual and Automatic Regulation of the Saw Gin Feed Rollers. Scientific Journal “Universum: Technical Sciences”. Part 2, 9, 22-26. https://7universum.com/ru/tech/archive/item/10693

[12] Umarov, A., Ortikova, K. and Sarimsakov, A. (2020) Analysis of Speeds of Cylinders of Saw Gins and Linters and Determination of Critical Frequencies for Them. Engineering, 12, 715-722. https://doi.org/10.4236/eng.2020.1210050

[13] Umarov, A.A., Kurbanov, D.M., Akhmedkhodjaev, Kh.T. and Ergashev, J.F. (2020) Improving the Roll Box of the Saw Gin. The American Journal of Engineering and Technology, 2, 50-53. https://usajournalshub.com/index.php/tajet/article/view/1444

[14] Umarov, A.A., Kurbanov, D.M., Akhmedkhodjaev, Kh.T. and Kenjaeva, M.I. (2020) Saw Gin Accelerator. International Journal of Academic Engineering Research, 4, 59-63. http://ijeais.org/wp-content/uploads/2020/11/IJAER201110.pdf

[15] Sarimsakov, A., Muradov, R. and Mardonov, B. (2020) Modeling of the Process of Interaction of the Saw Cylinder with the Raw Material in the Process of Ginning. TEST Engineering and Managemant (Scopus), 83, 27386-27391. http://testmagzine.biz/index.php/testmagzine/article/view/12709

[16] Sarimsakov, A.U., Ahmedov, B. and Abdullajanov, B. (2020) To Study Circling of the Seed Roller at Ginning Process with Practical Method. The American Journal of Engineering and Technology, 2, 142-148.

[17] Sarimsakov, A.U. and Ergashev, J.F. (2020) Modeling the Motion of a Mixture with Weighty Particles in a Stationary Flow of Liquid. SAARJ Journal on Banking \& Insurance Research (SJBIR), 9, 20-24. https://doi.org/10.5958/2319-1422.2020.00035.1

[18] Sarimsakov, A.U., Ortikova, K.I. and Muradov, R. (2020) The Influence of the Speed of the Seed Roll on the Efficiency of the Gin. Journal of Technical Research, 4, 36-43.

[19] Sarimsakov, A., Artikova, K. and Muradov, R. (2020) The Effect of the Speed of the Seed Roller on the Efficiency of the Gin Machine. Journal of Technical Research, 4, 36-43. https://www.technical.tadqiqot.uz/

[20] Sarimsakov, A. (2014) Modeling the Process of Interaction of a Moving Mass of Raw Cotton with a Rotating Saw Cylinder. Journal of Problems of Mechanics, 2, 122-125. 